\title{
V012 FROM SEISMIC IMPEDANCES TO RESERVOIR POROSITIES - THE ROAD IS NOT ALWAYS STRAIGHT
}

NATHALIE LUCET and FRÉDÉRIQUE FOURNIER Institut Français du Pétrole, PO Box 311, 92506 Rueil-Malmaison, France

\section{Introduction}

Seismic data are nowadays commonly used to improve the reservoir image between wells, with techniques for quantitative lithologic interpretation. In particular, when the reservoir is not too heterogeneous, it is standard to use seismic derived acoustic impedances to predict reservoir properties such as average porosities [1, 2]. Acoustic impedances are extracted from post-stack seismic amplitudes with inversion techniques. Then, they are turned into porosities with a regression approach (simple regression or eventually cokriging) after a calibration in the vicinities of wells. In this paper, a case study is used to examine some difficulties in this approach and to carry out sensitivity tests for defining critical parameters in the prediction of seismic porosities.

\section{Stratigraphic inversion of the seismic data}

The reservoir under study, located in North Sea, belongs to the Broom formation in the Brent group. It corresponds to fan delta deposits of clean coarse-grained sandstones. Average porosities vary from $17 \%$ to $30 \%$ at wells.

Preliminary to the post stack inversion, a well to seismic tie is carried out to extract a stable wavelet across the field. The methodology is based on a multi-well multi-trace approach [3]. Once the power spectrum is defined, a phase estimation is carried out on a set of traces around each well based on correlation analyses with the well synthetic trace to estimate the optimal phase rotation. Three parameters -correlation coefficient, time shifts, operator amplitude- are analyzed for determining a common wavelet over the field.

Stratigraphic inversion with a priori information is next carried out on the 3D seismic data set [3]. A 3D a priori model is built by ordinary kriging of the acoustic impedance logs at wells, along correlation surfaces related to depositional modes in stratigraphic units. These units are defined from structural and stratigraphic interpretation of the zero-phased 3D seismic data. The 3D a priori model undergoes a low pass filtering corresponding to the seismic bandpath. Then the $3 \mathrm{D}$ inversion algorithm updates the initial impedance model by integration of the seismic amplitude variations. It leads to an optimal acoustic impedance cube, with associated reflection coefficients. A refined picking of the Broom interval (top and bottom) was carried out on the inversion results. The Broom time window varies from 12 to $40 \mathrm{~ms}$. 


\section{Calibration of acoustic impedances in porosities}

Since vertical variations of the reservoir porosity are small in comparison with its lateral variations, and because of the limited seismic bandwidth, the target parameter is the porosity averaged over the Broom interval. The calibration is based on correlation analyses between parameters deduced from inverted seismic data around available wells and average porosity know at the wells.

Non stationarity of the data set: The crossplot at wells shows a linear trena between acoustic impedance and porosity, except for two wells acting like outliers. These two wells traduce a lateral variation of the fan delta deposits from coarse-grained to silty sediments. Before applying the calibration, it is compulsory to subdivide the data according to these two geological behaviors. To do so, seismic facies analysis [4] supervised by geological knowledge is performed on the seismic traces after inversion. Two facies are defined, one corresponding to the two "outliers" wells (silty reservoir) and the other to "classic" wells (coarse-grained sandstones). Result consists of a facies map defining lateral extension of the silty zone where the traces should not be calibrated with the linear trend defined on the classic wells.

Choice of the seismic parameters to be calibrated : The correlation analyses show that impedance value at $8 \mathrm{~ms}$ above the base of Broom provides a better calibration than the impedance averaged over the whole reservoir interval. Also, the choice of the trace to be related to the well in the calibration population is important. The synthetic trace at the well, the nearest real trace or a trace averaged over a neighborhood of the well can be used. The consequences of this choice on the porosity prediction are analyzed.

Influence of the a priori information incorporated through inversion : Two a priori impedance models, mainly distinct by their range of correlation, are built and their influence on the impedance after inversion, used in the calibration, is evaluated with statistics and spatial structure analysis.

The optimal impedance model after inversion includes a low frequency component. The effect of this component on the porosity estimation is studied.

\section{Conclusion}

These studies show that even in a case supposed to be simple, some pitfalls must be avoided on the road from seismic impedances to reservoir porosities. Non stationarity of the data should be detected, and can be overcome with facies analysis. Careful choice of the seismic attributes to calibrate is also important. Finally, a detailed exploration of the data is a key point in any quantitative lithologic interpretation.

\section{References}

[1] Brac, J., Déquirez, P.Y., Hervé, F., Jacques, C., Lailly, P., Richard, V., and Van Nhieu, D.T., 1992, Inversion with a priori information : An approach to integrated Stratigraphic Interpretation, in Sheriff, R. E., Ed., Reservoir geophysics: Doc. Expl. Geophys., Investigations in Geophysics 7, 251-258.

[2] Yang, C.T., et al., 1995, Integrated geostatistical reservoir description using petrophycal, geological, and seismic data for yacheng 13-1 gas field, SPE 30566, 357372. 
[3] Déquirez, P. Y., Fournier, F., Blanchet, C., Feuchtwanger, T., Torriero, D. 1995, Integrated stratigraphic and lithologic interpretation of the East-Senlac heavy oil pool, 65th Ann. Intern. Mtg., Soc. Expl. Geophys., p. 104-107.

[4] Fournier, F. and Derain, J.F., 1995, A statistical methodology for deriving reservoir properties from seismic data : Geophysics, 60, p. 1437-1450.

[5] Fournier, F., and Derain, J.F., 1992, Seismic data integration in reservoir simulations through a multivariate statistical calibration approach : 62nd Ann. Internat. Mtg., Soc. Expl. Geophys., Expanded Abstract, 95-98. 
